\section{Valsalva Experiment}

Q.-Can you give the physiological explanation of the afterdinner trick whereby the victim is rendered temporarily unconscious by strong compression of his chest, held fully expanded in deep inspiration, by the interlocked encircling arms of the operator? I have seen this performed only once, when the victim became unconscious for a few seconds after compression for about half a minute. He gave a slight convulsive jerk before regaining consciousness, which was immediate and full. The pulse was slow, full, and regular, and there was no aftereffect or ill feeling of any sort. I have found no record of tragedy, but I feel that this procedure must be potentially dangerous.

A.- It is possible to render a victim unconscious by strong compression of the chest aided by his natural reaction, which consists of forced expiration against a closed glottis. This is the Valsalva experiment, and if carried out sufficiently vigorously it halts the circulation, the intrathoracic pressure being so greatly raised as to prevent cardiac filling. In such circumstances loss of consciousness must be associated with absence of the pulse. The procedure is unlikely to be dangerous in healthy subjects. for the circulation is fully restored immediately the individual is released.

\section{Delirium Tremens}

\section{Q.-What is the best treatment for delirium tremens?}

A. - It is perhaps best to tide the patient over with small doses of alcohol and intramuscular injections of paraldehyde in doses of $2 \mathrm{dr}$. (8 g.) repeated at four-hourly intervals if necessary. Any form of adequate sedation will relieve delirium.

\section{Persistent Abdominal Sinus}

Q.-About a year ago a classical caesarean section was carried out in a woman of 22 with contracted pelvis due to spastic hemiplegia. The uterus was emptied and sutured with silk mattress sutures. The puerperium was uneventful except for a stitch abscess in the abdomen, which resolved after treatment by fomentations. The uterus involuted satisfactorily, though there is slight menorrhagia. After three months another abscess developed in one of the abdominal sutures and a piece of catgut was extruded; this was followed by a sinus which has persisted, and through which bleeding has occurred during the last three menstrual periods. Recently one of the uterine sutures was extruded through the sinus, which still persists and remains troublesome. What is the prognosis, and what further steps do you recommend?

A. - This patient would appear to have either a uterine fistula or an endometrioma of the abdominal wall, or both. A spontaneous cure is now unlikely, and there is little to be said for continuing conservative measures. Any operation, however, should be conservative in nature and should aim at complete excision of the scar and sinus and the restoration of normal uterine function. Preliminary studies by means of radio-opaque media injected along the sinus track, and also into the uterine cavity through the cervix, would probably be helpful. The operation is likely to be difficult and should be carried out by an experienced gynaecologist.

\section{NOTES AND COMMENTS}

Dicoumarol and Prothrombin Level-Dr. G. A. MatThews (Hemel Hempstead, Herts) writes: I was surprised to see in "Any Questions?" (July 2, p. 38) an answer mentioning the use of Russel viper venom for measuring the prothrombin time of patients on dicoumarol therapy. It has been conclusively shown ${ }^{1}$ that Russell viper venom, when used as a thromboplastin, does not measure the prothrombin content of plasma, and that the coagulation times obtained with this thromboplastin bear no recognizable relationship to the availability of prothrombin in a patient under treatment with dicoumarol. It follows from this that to attempt to control dicoumarol therapy by means of Russell viper venom as a thromboplastin can be positively dangerous, as several workers have discovered, ${ }^{3}$ though the blame is often wrongly put on the use of dicoumarol. Dicoumarol therapy is a safe procedure when brain thromboplastin is used, as in Quick's one-stage technique of measuring prothrombin times, as has been shown in my laboratory during the past two years. I trust, Sir, that you will see that steps are taken to correct the dangerous advocacy of a discredited method of controlling dicoumarol therapy.

Dr. A. F. Mohun (London, N.19) writes: There is now sufficient evidence available to justify the statement that the use of viper venom as a source of thromboplastin is fraught with danger to the patient, in that this reagent may on occasion fail to disclose that the prothrombin time is in fact approaching, or has already reached, a dangerous prolongation. Alternative reagents have hitherto consisted of saline extracts of acetone-dried human or rabbit tissue (usually brain). These are free from what has become known as the "viper venom effect." An even simpler form of extract has been devised by Dr. M. Toohey, of New End Hospital, Hampstead (personal communication). I understand that an account of this is in the press. Finally, I should like to express my personal opinion that your reply to the question would have performed a real service to clinicians and pathologists if it had confined itself solely to the statement that the control of dicoumarol therapy is achieved by aiming at keeping the patient's prothrombin time within the range of one and a half to two and a half times the normal control time, using the same reagents. It is still not sufficiently appreciated that " prothrombin indices" and "prothrombin percentages" are calculations whose only basis is the measurement of time. No advantage is gained by elaboration of the basic data. The calculating of "prothrombin percentages" implies that prothrombin is a chemical individual, and that saline dilutions of normal plasma truly imitate plasmas from patients receiving dicoumarol: neither of these implications can be substantiated-they are therefore not only unnecessary but possibly misleading. Although the chemistry of the prothrombin time reaction is obscure, the principles of the control of dicoumarol treatment are clear and well substantiated: Use a potent thromboplastin other than viper venom; measure the prothrombin time of the patient's plasma and that of a.normal control plasma (both within three to four hours of removal of the blood); regulate the dosage of dicoumarol with the aim that the time ratio shall lie between one and a half and two and a half. The method of collection of the blood and the interpretation of the results call for personal collaboration between pathologist and clinician.

\section{REFERENCES \\ 1 Biggs, R., and Macfarlane, R. G. (1949). J. clin. Path., 2, 33 \\ 2 Lempert, H. (1948). British Medical Journal, 1, 125. \\ 3 James, G. A. (1948). Ibid., 1, 475.}

Transient Giddiness.-Dr. David Cowan (Johannesburg) writes In "Any Questions?" (May 28, p. 968) a question was asked on the causes and treatment of momentary transient vertigo. A possible cause not mentioned in your answer, and one I have met with on several occasions, is that of cerumen in the ear, deep enough presumably to cause pressure on the tympanum. Syringing gives complete relief.

\section{Corrections}

The report of the meeting of the Section of Ophthalmology held on June 30, which appeared in our issue of July 9 (p. 92), incorrectly summarized $\mathrm{Dr}$. Alice Carleton's views. The last sentence reporting her observations does not represent her opinion.

In the account of the combined meeting of the Sections of Obstetrics and Gynaecology and Dermatology held on June 30, which appeared in our issue of July 9 (p. 88), Dr. Elizabeth Hunt is incorrectly reported to have said that in her experience psychogenic causes of pruritus vulvae were rare. In fact she said that pruritus vulvae due solely to psychogenic causes was in her experience rare.

In the report (July 16, p. 165) of Dr. W. Pointon Dick's remarks during the discussion on tuberculosis and occupation at the meeting of the Section of Occupational Health it was stated: "In return visits it was found that the rate of new cases per 100 examined was reduced by a third." This should have read "reduced to a third."

All communications with regard to editorial business should be addressed to THE EDITOR BRIST TAVISTOCK SQUARE, EDITOR, BRITISH MEDICAL Journal, B.M.A. House, TAVISTOCK SQUARE, LONDON, W.C.1. TELEPHONE: EUSTON 2111. TELEGRAMS: Aitiology, pestcent, London. ORIGINAL ARTIC to the British Medical Journal alone unless the contrary be stated.

Authors dhe Publishing Manager, B.M.A. House, Tavistock Square, W.C.1, on receipt of proofs. Authors B.M.A. House, Tavistock should indicate on MSS. if reprints are required, as proofs are not overseas should
sent abroad.

DVERTISEMENTS should be addressed to the Advertisement Manager. B.M. House, Tavistock Square, London, W.C.1 (hours 9 a.m. to 5 p.m.) TELEgrams: Britmedads, Westcent, London. TELEPE' SUASCRIPTIONS should be sent to the SECRETARY of th AELERAMS: Medisecra, Westcent Association

London.

B.M.A SCOTIISH OfFICE: 7, Drumsheugh Gardens, Edinburgh. 